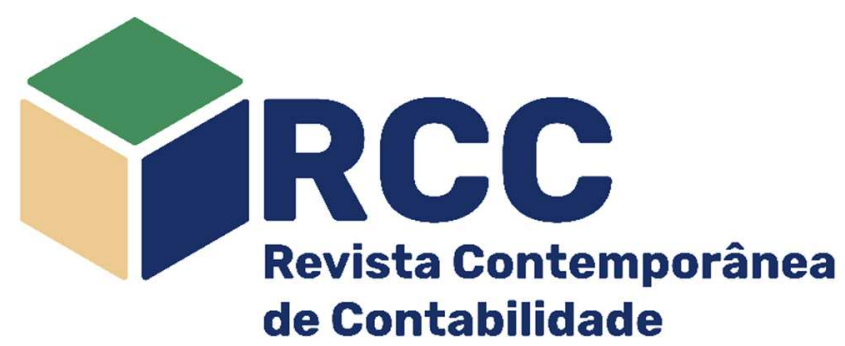

\title{
Análise da influência do audit delay no retorno das ações e no custo da dívida de empresa brasileiras de capital aberto
}

\author{
Analysis of the influence of audit delay on return on equity and cost of debt of Brazilian publicly \\ traded companies
}

Análisis de la influencia del retraso de la auditoría en la rentabilidad de las acciones y el costo de la deuda de las empresas brasileñas que cotizan en bolsa

\author{
Nikolle Takasawa Yagui \\ Graduanda em Economia Empresarial e \\ Controladoria (USP), Ribeirão Preto/SP, Brasil \\ nikolle.yagui@usp.br \\ https://orcid.org/0000-0001-7328-433X
}

\author{
Paula Carolina Ciampaglia Nardi ${ }^{\star}$ \\ Doutora em Administração de Organizações (USP) \\ Professora do Departamento de Ciências Contábeis da \\ FEARP (USP), Ribeirão Preto/SP, Brasil \\ paulanardi@fearp.usp.br \\ https://orcid.org/0000-0001-7897-3070 이
}

\section{Endereço do contato principal para correspondência*} Av. Bandeirantes, 3900, Monte Alegre, CEP: 14040-905 - Ribeirão Preto, SP, Brasil

\begin{abstract}
Resumo
No contexto da importância da informação contábil às principais fontes de recursos das empresas, o objetivo do estudo foi analisar o impacto do tempo (audit delay) na divulgação das demonstrações contábeis (DFPs) para investidores e instituições bancária. A pesquisa considerou empresas brasileiras de capital aberto no período trimestral de 2010 a 2017, via testes de correlação, diferença de média, regressão com dados dispostos em painel e quantílica. Os resultados indicaram haver reações distintas entre investidores e bancos, ou seja, o audit delay não apresentou impacto negativo no retorno das ações, mas foi negativo em termos de custo da dívida. Isso sugere que investidores e bancos apresentam percepções diferentes acerca do audit delay das DFPs. Assim, o estudo indica para as empresas a necessidade de refletir quanto ao custo de oportunidade de maior audit delay das DFPs, principalmente quando o objetivo é financiamento via instituições bancárias.
\end{abstract}

Palavras chave: Audit delay; Retorno das ações; Custo da dívida

\begin{abstract}
Within the context of the importance of accounting information for the main sources of corporate funds, the objective of the study was to analyze the impact of audit delay on Standardized Financial Statements (SFS) disclosure to investors and banking institutions. The research considered Brazilian publicly traded companies in the quarterly period from 2010 to 2017 , via correlation tests, mean difference, panel data regression and quantile regression. The results indicated that there were different reactions between investors and banks, that is, audit delay did not have a negative impact on return on equity, but it was negative in terms of cost of debt. This suggests that investors and banks have different perceptions of audit delay in SFS disclosure. Thus, the study indicates to companies the need to reflect on the opportunity cost of a larger audit delay in SFS disclosure, especially when the objective is financing via banking institutions.

Keywords: Audit delay; Return on equity; Cost of debt

\section{Resumen}

En el contexto de la importancia de la información contable para las principales fuentes de recursos corporativos, el objetivo del estudio fue analizar el impacto del tiempo (demora en la auditoría) en la divulgación de estados financieros (DFP) a inversionistas e instituciones bancarias. La encuesta consideró las empresas brasileñas que cotizan en bolsa en el período trimestral de 2010 a 2017, mediante pruebas de correlación, diferencia de medias, regresión con datos de panel y cuantiles. Los resultados indicaron que hubo diferentes reacciones entre inversionistas y bancos, es decir, el retraso de la auditoría no tuvo un impacto
\end{abstract}


negativo en la rentabilidad de las acciones, pero sí en el costo de la deuda. Esto sugiere que los inversores y los bancos tienen diferentes percepciones sobre el retraso de la auditoría de los DFP. Así, el estudio indica a las empresas la necesidad de reflexionar sobre el coste de oportunidad del mayor retraso en la auditoría de las DFP, especialmente cuando el objetivo es la financiación a través de entidades bancarias.

Palabras clave: Retraso de auditoría; Rendimiento de las acciones; Costo de la deuda

\section{Introdução}

O mercado de capitais e os bancos, como principais usuários da informação contábil, são importantes para o desenvolvimento econômico do país, e estão intimamente ligados à necessidade das informações contábeis, uma vez que a fidedignidade e a disponibilidade dessas informações é condição importante para o funcionamento do mercado e tomada de decisão dessas fontes de recursos (Dantasm \& Medeiros, 2015; Healy \& Palepu, 2001). Nesse sentido, Niyama (2005) considera a contabilidade como elemento importante para permitir aos usuários avaliar a situação econômica e financeira da empresa e dos riscos de investimentos, sendo que as Demonstrações Financeiras Padronizadas (DFPs) torna-se o elo entre empresas e usuários, com condições de auxiliar na formação base do conjunto de informações para decisão. Logo, a credibilidade dessas informações é considerada peça-chave aos usuários (Pevzner, Xie, \& Xin, 2015).

A importância da informação contábil para os usuários é respaldada pela relação de agência. Nesse cenário, é possível afirmar que as informações contábeis são ferramentas imprescindíveis para a redução dos efeitos da assimetria de informação (Chung, Judge, \& Li, 2015). Todavia, segundo Jensen e Meckling (1976), a assimetria informacional pode gerar desconfiança dos usuários sobre o conteúdo das demonstrações, já que apenas os gestores possuem acesso aos dados internos da empresa, possibilitando a possível intervenção destes nos relatórios, de modo que, ao gerenciar resultado, o agente pode atuar de forma oportunista, em detrimento do retorno ao principal (Healy \& Whalen, 1999; Schipper, 1989).

Nesse ponto, o gerenciamento de resultado pode iludir o usuário quanto a real rentabilidade da empresa, aumentando a assimetria informacional e a insegurança na tomada de decisão (Nardi \& Nakao, 2009), já que há uma relação direta entre qualidade da informação contábil e retorno de capital aos investidores (Easley \& O'hara, 2005). Portanto, quanto maior a qualidade das informações, menor a assimetria de informações, reduzindo a imprecisão aos usuários (Silva, Nardi, \& Tonani, 2016).

Nesse sentido, cabe ressaltar a característica qualitativa de tempestividade da informação contábil, que significa uma informação acessível em tempo hábil aos tomadores de decisão, de modo a influenciá-los em suas decisões, consequentemente, melhorar a eficiência de seus investimentos (Alkhatib \& Marji, 2012). Logo, caso a informação contábil não seja disponibilizada tempestivamente, após a finalização do período contábil, ela perde seu valor econômico (Al-Ajmi, 2008), afetando a competência e o funcionamento econômico do mercado (Alkhatib \& Marji, 2012).

Nesse contexto, algumas pesquisas vêm analisando os determinantes do tempo da entrega das DFPs, mais propriamente, a diferença entre a data de fechamento do exercício e a divulgação da informação ao mercado, assim como a diferença entre a data de fechamento e a data de assinatura das demonstrações (audit delay). Tais estudos identificaram que possíveis determinantes desse tempo são: i) tamanho da empresa (Al-Ghanem \& Hegazy, 2011; Abidin \& Ahmad-Zaluki, 2012; Alkhatib \& Marji, 2012; Cohen \& Leventis, 2013); ii) rentabilidade (Al-Ajmi, 2008; Abidin \& Ahmad-Zaluki, 2012; Alkhatib \& Marji, 2012; Cohen \& Leventis, 2013); iii) alavancagem (Al-Ajmi, 2008; Alkhatib \& Marji, 2012; Ahmad, Mohamed, \&; Nelson, 2016; Cohen \& Leventis, 2013); iv) tipo de relatório de auditoria, sendo que os modificados são divulgados depois dos relatórios não modificados e, quanto mais grave a modificação, maior o AD (Soltani, 2002); v) as empresas com maior número de acionistas e com maior endividamento tendem a divulgar o relatório mais rápido (Barcellos, Costa Júnior, \& Laurence, 2014); vi) mudança de auditor (Abidin \& Ahmad-Zaluki, 2012; Ng \& Tai, 1994; Whitworth \& Lambert, 2014); vii) governança corporativa (Kirch, Lima, \& Terra, 2012); viii) perda (Sharma, Tanyi, \& Litt, 2017; Whitworth \& Lambert, 2014); ix) liquidez da empresa (Al-Ghanem \& Hegazy, 2011; Cohen \& Leventis, 2013); x) taxa da auditoria (audit fee) (Palmrose, 1986).

Todavia, apesar de haver pesquisas que observam fatores que impactam o retorno das ações das empresas (Abidin \& Ahmad-Zaluki, 2012; Barcellos et al., 2014; Robu \& Robu, 2015; Pevzner et al., 2015; Lei, Wang, \& Yan, 2017; Souza \& Nardi, 2018) e no custo da dívida das empresas (Nardi \& Nakao, 2009; Eliwa, Haslam, \& Abraham, 2016; Lugo, 2017), não se observou trabalhos com a prerrogativa de observar a relação entre o tempo na entrega das DFPs e o retorno das ações e o custo da dívida.

Sendo assim, dada a importância da informação contábil para o mercado de capitais, a existência de estudos internacionais que analisam os determinantes do audit delay, das poucas pesquisas nacionais sobre essa relação, e por não se observar estudos que analisaram o impacto dos audit delay para os principais usuários da informação contábil, surge o interesse em observar a seguinte questão de pesquisa: Qual o impacto do audit delay no retorno das ações e no custo da dívida das empresas brasileiras de capital aberto? Desse modo, o objetivo do estudo é compreender os efeitos que o tempo na entrega das DFPs pode ocasionar em termos de retorno das ações e de custo de captação via instituições bancárias. Assim, com tais resultados, espera-se poder evidenciar às empresas brasileiras de capital aberto, o impacto que o tempo para divulgação 
das DFPs pode causar em suas principais fontes de captação de recursos, de modo que elas possam refletir e ponderar quanto ao custo de oportunidade de um maior ou menor audit delay.

\section{Referencial Teórico}

\subsection{Importância da Informação Contábil}

Uma das incitações da economia está relacionada ao encaminhamento dos recursos dos poupadores para os investimentos, de modo que a alocação eficiente de recursos deveria ser conduzida aos investimentos economicamente viáveis. Se esse processo de alocação de recursos for eficiente, então, há uma distribuição de maneira econômica, estimulando as principais fontes investidoras, consequentemente auxiliando a captação de recursos por parte das empresas captadoras. Além disso, para que a competência do mercado se mantenha, o valor de uma empresa deve refletir toda a informação disponível acerca dela, de modo que as fontes de recursos possam tomar suas decisões quanto à destinação de seus investimentos em ambiente com redução de incertezas (Souza \& Nardi, 2018).

Por isso, a qualificação das fontes de recursos sobre uma firma é mais forte quando as informações divulgadas refletem com fidedignidade o valor econômico divulgado e são percebidas como confiáveis (Hohenfels, 2016). Porém, uma adversidade implícita reside no fato de os usuários da informação não conseguirem observar o real desempenho econômico de uma empresa (Healy \& Whalen, 1999), tornando a manipulação dos dados, por parte da administração da firma, mais propensa a acontecer. $E$ isso pode ocorrer em função da relação agente-principal estabelecida na Teoria de Agência (Jensen \& Meckling, 1976).

Essa relação geralmente é caracterizada pela discrepância na quantidade e qualidade de informações que o principal e o agente possuem, sendo que este último pode criar obstáculos para o bom funcionamento do mercado (Kirch et al., 2012). Assim, quando não há alinhamento desses interesses, eclodem os problemas de conflitos de interesses (Jensen \& Meckling, 1976), gerados pela assimetria das informações, circunstância em que uma das partes de uma operação não provem de informação fundamental para analisar 0 desempenho dos envolvidos, seja firma ou usuários (Akerlof, 1970).

Nesse sentido, os relatórios contábeis se configuram como peças importantes para a relação entre poupadores e captadores mercado (Chen, Chen, \& Su, 2001; Kirch et al., 2012), capaz de diminuir os efeitos da assimetria informacional (Rocha, Pereira, Bezerra, \& Nascimento, 2012). Isso porque, as informações contábeis tem condições de reduzir a disparidade do conteúdo informacional, minimizando o conflito de agência, auxiliando os usuários da informação na tomada de decisão e reduzindo os custos de capital (Kirch et al., 2012).

Todavia, esse processo deve estar pautado em informações confiáveis e transparentes, pois a compreensão da credibilidade da informação contábil se faz uma determinante chave da reação das fontes de recursos (Boone, Khurana, \& Raman, 2010; Chung et al., 2015; Dantas \& Medeiros, 2015; Healy \& Palepu, 2001; Pevzner et al., 2015; Nardi \& Nakao, 2009). Posto isso, uma maior qualidade divulgação dos relatórios financeiros gera um aumento da fidedignidade dos usuários da informação, podendo gerar maiores retornos e menores custos para as empresas (Boone et al., 2010).

\subsection{Qualidade da Informação Contábil}

Dada a importância da qualidade da informação contábil para o melhor funcionamento da relação entre poupadores e captadores de recursos, é válido considerar a necessidade de que essa informação tenha certas características qualitativas, para melhor embasar as decisões de investimentos das principais fontes de recurso das empresas, quer sejam os investidores ou os bancos. Nesse sentido, de acordo com o CPC 00 (2011), a informação contábil-financeira útil possui características qualitativas fundamentais, como a relevância, a materialidade e a representação fidedigna, e de melhoria, como por exemplo, a comparabilidade, a verificabilidade, a tempestividade e a compreensibilidade. Com isso, para que a utilidade da informação seja melhorada, esta deve ser relevante e ser representada com fidedignidade.

Dentre as características citadas, a tempestividade implica em dispor informações acessíveis aos usuários da informação a tempo de influenciá-los em suas decisões, persuadindo, assim, a relevância do dado contábil (Barcellos et al., 2014), consequentemente, melhorando a eficiência das alocações de recursos (Alkhatib \& Marji, 2012).

Nesse sentido, uma vez que um dado mais antigo possui menos utilidade, a não ser que o usuário da informação necessite identificar e avaliar tendências da firma, então, quanto mais elevado o grau de defasagem entre o final do exercício e a publicação das demonstrações, menor será a importância dessa informação (Barcellos et al., 2014) e sua relevância (Beaver, 1968). Ainda nesse contexto, de acordo com o SFAC No.2 (FASB, 1980), uma informação contábil é considerada relevante quando auxilia a prever ou confirma acontecimentos financeiros dentro da esfera empresarial. Posto isso, caso a informação não seja disponibilizada num intervalo de tempo pequeno após a data da finalização do período contábil, ela perde utilidade em seu valor econômico. 
A tempestividade também se destaca por ser um meio de minimização da assimetria de informações e redução de oportunismo nos rumores dos spreads acionários, isto é, diferença de preço de compra e venda de uma ação, sobre o desempenho da firma (Al-Ajmi, 2008), fatores esses que auxiliam os usuários da informação contábil na tomada de decisões, resultando numa provável influência nos valores de ações (AlGhanem \& Hegazy, 2011) e nas preferências das fontes de investimentos (Habib \& Bhuiyan, 2011).

Entretanto, os gestores possuem a liberdade de escolher quando divulgar o relatório no período que abrange o encerramento do processo de elaboração das DFPs e o prazo normativo descrito. Por essa razão, a escolha do momento da publicação é feita de forma oportuna, determinada por incentivos para antecipá-la ou atrasá-la, afetando diretamente o aspecto da relevância da informação (Barcellos et al., 2014).

Dado o contexto de importância da informação contábil nos processos de alocação de recursos pelas principais fontes, como investidores e bancos, e da necessidade de analisar eficiências para o melhor funcionamento desses mercados, há uma linha de pesquisa que vem buscando investigar causas e consequências do maior tempo gasto pelas empresas em divulgar suas DFPs. Esse tempo gasto entre a data de fechamento das DFPs e sua divulgação é denominado de Audit Delay (AD) (Bonsón-Ponte, EscobarRodríguez, \& Borrero-Domínguez, 2008).

Tais estudos verificaram que o AD está relacionado com métricas contábeis inferiores e problemas na geração de informação contábil (Dopuch, Holthausen, \& Leftwich, 1986; KRISHNAN; YANG, 2009) que, por sua vez, podem ocasionar em cenários de maior incerteza aos investidores e bancos. Isso porque, maior tempo para entrega das DFPs pode ser consequência de problemas no controle interno, complexidade de processos, volume de atividades ou mesmo gerenciamento de resultados que acabam por dificultar os processos de auditoria externa (Linn \& Dihel, 2005). Nesse sentido, maior tempo para divulgar as DFPs pode dificultar a previsibilidade de resultados futuros, obstando o embasamento de decisões de alocação de recursos pelos poupadores (Nardi, Amadi, \& Silva, 2019). Tal cenário pode dificultar o acompanhamento dos bancos em empréstimos realizados pelas empresas (Kim, Song, \& Tsui, 2013), viabilizando a possibilidade dos mesmos exigirem informações com um nível de qualidade mais elevado (Slovin, Sushka, \& Hudson, 1990)Além disso, o AD, segundo Knechel e Payne (2001), reduz o poder informativo das DFPs, indicando maior assimetria de informação Também pode ser visto como um fator que restringe a relevância das DFPs (Dong, Robinson, \& Xu, 2018), o que pode interferir negativamente no processo decisório dos usuários, além de aumentar a incerteza (Beiruth, Brugni, Fávero, \& Goes, 2014).

\section{Metodologia}

O estudo trabalhou com empresas brasileiras não financeiras de capital aberto listadas na B3, no período trimestral de 2010 a 2017. As informações foram coletadas do banco de dados Economática e do sitio da B3. Com relação aos métodos de análise, iniciou-se com os testes de normalidade (KolmogorovSmirnov), correlação (Spearman), diferença de média (U de Mann-Whitney), em que o valor do retorno das ações e do custo da dívida foram ordenados conforme ordem crescente de cada variável, separados nos quartis extremos, 1 e 4, para cada variável, diante dos quais foram calculada as médias de retorno e custo da dívida para analisar se há diferença estatística entre elas.

Na sequência, foi aplicada regressão múltipla com dados dispostos em painel e regressão quantílica, para uma análise entre as diferenças dos grupos pequeno, médio e grande de empresas em relação ao retorno e ao custo da dívida.

O objetivo da sequência de testes definidos foi dar robustez das análises, observando deste a relação entre duas variáveis (correlação e diferença de média) à análise conjunta (regressões). Cabe destacar que, no caso dos modelos de regressão, foram realizados testes para observações dos pressupostos da regressão, como: i) heterocedasticidade, ii) multicolinearidade e iii) correlação serial, bem como testes para indicar uso de Pooling, efeitos fixos ou efeitos aleatórios

Os modelos pré-definidos para análise de regressão foram:

$$
\begin{aligned}
& \quad \begin{array}{l}
\text { Retorno }=\alpha_{i t}+\beta_{1} x \operatorname{AD}_{\mathrm{it}}+\beta_{2} \mathrm{xTam}_{\mathrm{it}}+\beta_{3} \mathrm{xEndiv}_{\mathrm{it}}+\beta_{4} \mathrm{xDesemp}_{\mathrm{it}}+\beta_{5} \mathrm{xGC}_{\mathrm{it}}+\beta_{6} \mathrm{xLiq}_{\mathrm{it}}+ \\
+\beta_{7} \mathrm{xBig}_{\mathrm{it}}+\beta_{8} \mathrm{xMg}_{\mathrm{it}}+\beta_{9} \mathrm{xCres}_{\mathrm{it}}+\beta_{10} \mathrm{xIdad}_{\mathrm{it}}+\beta_{11} \mathrm{xAlav}_{\mathrm{it}}+\varepsilon_{\mathrm{it}}
\end{array} \\
& \mathrm{Ki}=\alpha_{\mathrm{it}}+\beta_{1} \mathrm{xAD}_{\mathrm{it}}+\beta_{2} \mathrm{xTam}_{\mathrm{it}}+\beta_{3} \mathrm{xEndiv}_{\mathrm{it}}+\beta_{4} \mathrm{xDesemp}_{\mathrm{it}}+\beta_{5} \mathrm{xRisco}_{\mathrm{it}}+\beta_{6} \mathrm{xGC}_{\mathrm{it}}+\beta_{7} \mathrm{xLiq}_{\mathrm{it}}+ \\
& +\beta_{8} \mathrm{xMg}_{\mathrm{it}}+\beta_{9} \mathrm{xBig}_{\mathrm{it}}+\beta_{10} \mathrm{xCres}_{\mathrm{it}}+\beta_{11} \mathrm{xIdad}_{\mathrm{it}}+\beta_{12} \mathrm{xAlav}_{\mathrm{it}}+\beta_{13} \mathrm{xTang}_{\mathrm{it}}+\beta_{11} \mathrm{xVolat}_{\mathrm{it}}+\varepsilon_{\mathrm{it}}
\end{aligned}
$$

Em que:

Retorno: retorno das ações, calculado mediante metodologia de Brooks (2002), dividindo $\mathrm{P}_{\mathrm{t}}$ (obtido pela média do preço das ações 5 dias após a divulgação das DFPs) por $\mathrm{P}_{\mathrm{t}-1}$ (média do preço das ações 5 dias antes da divulgação das DFPs);

Ki: Custo da dívida, calculado por meio da relação entre a despesa financeira líquida e passivo oneroso total; 
AD: representa a diferença entre a data de fechamento e a divulgação das DFPs. É esperada uma relação negativa com o retorno das ações (Al-Ghanem \& Hegazy, 2011; Cohen \& Leventis, 2013; Habib \& Bhuiyan, 2011), uma vez que quanto maior os valores em relação ao audit delay, pior pode ser a situação da empresa (Oliveira, Cunha, Santo, Faveri, \& Junior, 2014). Nesse caso, há a possibilidade da empresa possuir problemas em relação às suas DFPs (Pereira \& Costa, 2012), como, por exemplo, o gerenciamento de resultados. Em relação ao custo da dívida, espera-se uma relação positiva (Alzoubi, 2018; Gong, Li, \& Yin, 2019; Al-Ghanem \& Hegazy, 2011; Cohen \& Leventis, 2013), já que as instituições bancárias valorizam a tempestividade das informações e informação de qualidade (Alzoubi, 2018). Portanto, quando mais tempo a empresa leva para divulgar os resultados, mais arriscada é considerada;

Tam: tamanho das empresas, calculado pelo logaritmo do Ativo Total. É esperado uma relação positiva com o retorno das ações (Chen, Kim, \& Yao, 2017; García, Alejandro, Sáenz, \& Sánchez, 2017; Pornupatham, 2015; Souza \& Nardi, 2018) e negativa com o custo da dívida (Eliwa et al., 2016; Lugo, 2017; Nardi \& Nakao, 2009), pois empresas maiores apresentam maior credibilidade em contratos de dívidas, uma v ez que há mais ativos para serem garantias e, muitas vezes, se concentram no oferecimento de diversos bem e/ou serviços, tornando-se a falência menos provável (Valle, 2007);

Endiv: endividamento da empresa, calculado pela relação entre passivo financeiro de curto e longo prazo pelo ativo total. O cálculo utilizou o passivo oneroso, com o intuito de isolar o possível efeito dos financiamentos, empréstimos e encargos financeiros derivados dos empréstimos de curto e longo prazo. É esperada uma relação negativa com o retorno das ações, visto que empresas com maiores níveis de endividamento possuem menor flexibilidade para financiar suas atividades (Artiach, Lee, Nelson, \& Walker, 2010), o que pode prejudicar seu desempenho. Também é esperada uma relação negativa com o custo da dívida (Lugo, 2017; Nardi \& Nakao, 2009), já que, no geral, empresas com menor nível de endividamento, porém, maior volume de ativos intangíveis, deveriam apresentar maior custo da dívida, dado que a ausência de garantias eleva o custo (Perobelli \& Famá, 2003);

Desemp: desempenho, calculado pela relação entre lucro líquido e a diferença entre ativo total e lucro líquido. É esperada uma relação positiva com o retorno, pois maior desempenho pode aumentar o valor da empresa, consequentemente, a riqueza dos acionistas (Bastos, Nakamura, David, \& Rotta, 2009). Também é esperada uma relação positiva com o custo da dívida, pois maior desempenho pode significar a expansão da estrutura de capitação da empresa e, consequentemente, seu custo da dívida aumenta (Chen et al., 2017; Lugo, 2017; Souza \& Nardi, 2018). No entanto, para as instituições bancárias, um aumento no desempenho da empresa, pode sinalizar redução da probabilidade de inadimplência (Barros, Silva, \& Voese, 2015), ocasionando em taxas de financiamento mais baixas. Risco: risco das empresas, calculado pela relação entre passivo total e ativo total. Variável também utilizada por Silva e Nardi $(2014,2017)$ Espera uma relação positiva com o custo da dívida, visto que as empresas conseguem diminuir seu custo quando dão mais garantias, já que diminui seu risco (Kayo \& Famá, 2004; Pornupatham, 2015);

GC: variável dummy que assume 1 se a empresa estiver listada nos Níveis de Governança Corporativa da Bovespa e 0 , caso contrário. É esperada uma relação positiva com retorno das ações, já que a prática da Governança Corporativa busca reduzir a assimetria informacional e, com isso, há expectativa de que as demonstrações das firmas sejam mais transparentes. Além disso, essa prática leva ao aumento da credibilidade do gestor, atrai mais investidores e melhora a avaliação dos preços das ações (Lima, 2009). Com relação ao custo da dívida, é esperada relação negativa, uma vez que um dos benefícios de uma maior transparência das demonstrações das empresas é a redução do custo de capital tanto de terceiros, como o próprio (Lima, 2009), pois a informação contábil influencia diretamente o custo de capital das organizações (Lambert, Leuz, \& Verrecchia, 2007);

Liq: liquidez das empresas, calculada através da relação entre a diferença de ativo circulante e itens não caixa pelo passivo circulante. É esperada uma relação positiva com retorno das ações, já que os indicadores de liquidez das organizações evidenciam sua saúde financeira. Com relação ao custo da dívida é esperada relação negativa (Hopp \& Leite, 1989);

Big4: variável dummy, sendo 1 para empresas auditadas por Big Four e 0, caso contrário. Espera-se uma relação positiva com o retorno (Firmino, Damascena, \& Paulo, 2010) e negativa para custo da dívida (Arruda, Sousa, Pena, Paulo, \& Paulo, 2012; Souza \& Nardi, 2018);

Mg: margem líquida da empresa, calculada pela relação entre Lucro Líquido e Receitas de Vendas. Espera-se uma relação positiva para o retorno e o custo da dívida da relação de lucro líquido por receita de vendas, assim como foi testado em estudos prévios (Robu \& Robu, 2015; Souza \& Nardi, 2018);

Cresc: crescimento da empresa, calculado de acordo com a variação da receita de vendas, esperando um resultado positivo para o retorno e o custo da dívida (García et al., 2017; Gomariz \& Ballesta, 2014; Silva et al., 2016; Souza \& Nardi, 2018);

Idad: idade da empresa, em que se espera uma relação positiva com o retorno e negativa com o custo da dívida, já que empresas mais antigas apresentam histórico de longo prazo para análise de suas condições financeiras (Lugo, 2017; Nardi \& Nakao, 2009);

Alav: Alavancagem da empresa, calculado pela relação entre o ativo total e o patrimônio líquido da empresa. Espera-se uma relação positiva para o retorno e o custo da dívida (Eliwa et al., 2016; Chen et al., 2017), pois empresas com maiores alavancagens estão mais propensas a escolher métodos contábeis que provoquem aumentos no lucro reportado (ludícibus \& Lopes, 2004), enquanto que empresas com mais dívidas podem ser vistas como mais arriscadas (Nardi \& Nakao, 2009).

Tang: tangibilidade, calculado através da diferença de imobilizado líquido dividido pelos ativos totais. Espera-se uma relação negativa com o custo da dívida, uma vez que, ao representar a relação de ativos a serem dados em garantia nos contratos de dívidas, reduz a possibilidade do tomador emitir dívidas adicionais sobre esse ativo (Valle, 2007); Volat: Volatilidade, calculado pelo desvio-padrão do fluxo de caixa operacional, esperando-se uma relação positiva com o custo da dívida (Lei et al., 2017; Chen et al., 2017; Nardi \& Nakao, 2009). 


\section{Apresentação e Análise dos Resultados}

Com o intuito de observar aspectos importantes das variáveis utilizadas no modelo, a estatística descritiva pode ser observada na Tabela 1.

\begin{tabular}{|c|c|c|c|c|c|}
\hline & Media & Mediana & Desvio Padrão & Minimo & Máximo \\
\hline Retorno & 0,999 & 0,997 & 0,069 & 0,723 & 2,061 \\
\hline $\mathrm{Ki}$ & 0,266 & 0,187 & 0,216 & 0,100 & 1,393 \\
\hline$A D$ & 45,630 & 43,0 & 19,233 & 7,0 & 299,0 \\
\hline Tam & 15,037 & 15,057 & 1,716 & 9,584 & 20,652 \\
\hline Endiv & 0,224 & 0,206 & 0,182 & 0,0 & 0,982 \\
\hline Desemp & 0,057 & 0,039 & 0,065 & 0,0 & 0,781 \\
\hline Risco & 0,566 & 0,565 & 0,197 & 0,013 & 0,999 \\
\hline Liquidez & 1,340 & 1,204 & 0,798 & 0,015 & 4,998 \\
\hline $\mathrm{Mg}$ & 0,029 & 0,041 & 0,315 & $-1,999$ & 1,928 \\
\hline Cresc & 0,061 & 0,073 & 0,249 & $-0,995$ & 0,991 \\
\hline Alavan & 2,487 & 2,227 & 1,124 & 0,225 & 5,994 \\
\hline Idade & 18,664 & 11,433 & 15,055 & 0,0 & 75,681 \\
\hline $\mathrm{GC}$ & 0,740 & 1,0 & 0,439 & 0,0 & 1,0 \\
\hline Big4 & 0,810 & 1,0 & 0,392 & 0,0 & 1,0 \\
\hline Tangil & 0,236 & 0,195 & 0,220 & 0,0 & 0,899 \\
\hline Volat & 0,027 & 0,018 & 0,030 & 0,001 & 0,199 \\
\hline
\end{tabular}

Analisando a Tabela 1 se percebe que, com exceção do custo da dívida, as variáveis apresentam valor médio próximo à mediana, sinalizando que os dados não estão fortemente impactados pelos valores extremos. Cabe ressaltar que, no caso da variável Audit Delay, tem-se duas empresas com valores destoantes das demais, quanto ao tempo de entrega das DFPs, sendo uma delas a Petrobrás. Se retirada essas empresas, há uma maior aproximação da média e da mediana, bem como redução do desvio padrão da variável.

Apesar de termos, no geral, valores médios e medianos próximos, em termos de variabilidade, ou seja, observando a diferença entre valores mínimos e máximos, é possível perceber que há variabilidade nos dados.

Observando a dispersão dos dados, por meio do desvio padrão, percebe-se maior dispersão para o custo da dívida, endividamento, desempenho, margem, crescimento, idade, tangibilidade e volatilidade. Tais análises sinalizam para uma heterogeneidade dos dados.

\subsection{Análise para retorno das ações}

Para análise da relação entre audit delay e o retorno das ações, inicialmente foi observada a correlação entre as variáveis por meio do teste de Spearman (Tabela 2). Em seguida, prosseguiu-se com aplicação do teste de diferença de média (Tabela 3), sendo que, para cada variável independente definida no estudo, o retorno das ações foi ordenado de modo crescente, em seguida, separaram-se os extremos (quartis 1 e 4), calculando a média de retorno para cada caso.

Tabela 1:

Correlação de Spearman para retorno

\begin{tabular}{lc}
\hline \multicolumn{2}{c}{ Retorno } \\
\hline AD & 0,0015 \\
Tam & 0,023 \\
Endiv & $-0,0373^{\star *}$ \\
Desemp & $0,0912^{\star * *}$ \\
Liquidez & $0,0554^{\star * *}$ \\
Mg & $0,1515^{\star \star *}$ \\
Cresc & $0,1028^{\star * *}$ \\
Alavanc & $-0,367^{\star *}$ \\
Idade & $-0,117$ \\
GC & $-0,0191$ \\
Big4 & 0,0218 \\
\hline Sendo ${ }^{* \star *},{ }^{* *} \mathrm{e}^{*}$ significante a $1 \%, 5 \% \mathrm{e} 10 \%$.
\end{tabular}

Tabela 2:

Diferença de média para retorno

\begin{tabular}{cccc}
\hline & Q1 & $\mathbf{Q 4}$ & $\mathbf{z}$ \\
\hline AD & 1,003351 & 1,005115 & $-0,43$ \\
Tam & 0,9998908 & 0,9985309 & $-2,059^{* *}$ \\
Endiv & 1,000929 & 0,9980934 & $2,14^{* *}$ \\
Desemp & 0,9903915 & 1,00347 & $-6,028^{* * *}$ \\
Liquidez & 0,9957559 & 1,001198 & $-4,118^{* * *}$ \\
Mg & 0,9863168 & 1,006172 & $-9,82^{* * *}$ \\
Cresc & 0,9900366 & 1,001704 & $-5,795^{\star * *}$ \\
Alavanc & 1,002387 & 0,9955951 & $2,877^{* * *}$ \\
Idade & 1,001068 & 1,00265 & 1,295 \\
GC & 1,002354 & 0,9976485 & 1,249 \\
Big4 & 0,9997571 & 0,9986662 & $-1,878^{* *}$ \\
\hline
\end{tabular}

Para dar robustez à pesquisa, foi realizado a análise por regressão com dados dispostos em painel (Tabela 4), sendo que, para efetivação dessa análise foram aplicados testes para identificar a indicação para uso de dados em Pooling (Pool), efeitos fixos ou efeitos aleatórios. Para decidir entre efeito aleatório e Pool 
foi aplicado o teste de Breusch Pagan Lagrangian, entre efeito fixo e Pool foi usado o teste de F de Chow e entre efeito aleatório e efeito fixo, o teste de Hausman. Os resultados indicaram o uso do efeito fixo, apresentando problemas de heterocedasticidade, analisada por meio do teste de Wald, porém sem problemas de correlação serial e multicolinearidade, testadas pelos testes de Wooldridge (2012) e VIF, respectivamente.

Tabela 3:

Análise de regressão para retorno

\begin{tabular}{|c|c|c|}
\hline Variáveis & Coeficiente & $\mathbf{z}$ \\
\hline$A D$ & 0,0001128 & $2,13^{* *}$ \\
\hline Tam & $-0,0001032$ & $-0,15$ \\
\hline Endiv & $-0,0034856$ & $-0,7$ \\
\hline Desemp & 0,0122377 & $2,28^{* *}$ \\
\hline Liquidez & 0,0007501 & 1,43 \\
\hline $\mathrm{Mg}$ & 0,0016056 & $3,31^{\text {***}}$ \\
\hline Cresc & 0,0039024 & $1,9^{*}$ \\
\hline Alavanc & $-0,0003689$ & $-1,72^{*}$ \\
\hline Idade & $-0,0000222$ & $-0,3$ \\
\hline GC & $-0,0051517$ & $-1,88^{*}$ \\
\hline Big4 & $-0,0007863$ & $-0,26$ \\
\hline Constante & 0,9999708 & $98,09^{* * *}$ \\
\hline $\mathrm{F}$ & \multicolumn{2}{|c|}{$33,42^{\star \star *}$} \\
\hline$X^{2}$ & \multicolumn{2}{|c|}{0,04} \\
\hline Breusch-Pagan Lagrangian & \multicolumn{2}{|c|}{$11,93^{\star * *}$} \\
\hline Teste F de Chow & \multicolumn{2}{|c|}{$3,03^{* * *}$} \\
\hline Teste de Hausman & \multicolumn{2}{|c|}{$54,95^{\star \star *}$} \\
\hline Teste de Wald & \multicolumn{2}{|c|}{$8630,74^{\star * *}$} \\
\hline VIF & \multicolumn{2}{|c|}{1,23} \\
\hline Teste de Wooldridge & \multicolumn{2}{|c|}{0,015} \\
\hline
\end{tabular}

Por fim, foi analisada a regressão quantílica (Tabela 5). Tanto para análise de correlação, diferença de média e regressão múltipla, os resultados indicaram uma relação positiva entre o tempo na entrega das DFPs e o retorno das ações. Esse resultado também foi corroborado na análise quantílica, para qualquer que seja o nível de quartil (Q10, Q50 ou Q90), desde que considere retornos positivos. Esse resultado contraria o que era esperado pela literatura (Al-Ajmi, 2008; Al-Ghanem \& Hegazy, 2011; Cohen \& Leventis, 2013; Habib \& Bhuiyan, 2011; Payne \& Jensen, 2002). Uma possível justificativa para isso é que o tempo na entrega dos resultados do exercício da empresa permite que a empresa proceda com uma melhor revisão e escolhas de métodos contábeis (Skinner, 1994; Watts \& Zimmerman, 1986; Trueman, 1990). Nesse sentido, Lambert, Brazel e Jones (2007) identificaram que maior tempo na entrega das DFPs está associado com maior qualidade dos resultados, o que pode ser captado pelos investidores. Ainda é possível considerar que, diante de maior tempo na entrega das DFPs, o mercado pode antecipar algumas informações, de modo a anular o possível efeito negativo relativo ao próprio tempo

Tabela 4: Análise quantílica para retorno

\begin{tabular}{|c|c|c|c|c|c|c|}
\hline & \multicolumn{2}{|c|}{ Q10 } & \multicolumn{2}{|c|}{ Q50 } & \multicolumn{2}{|c|}{ Q90 } \\
\hline & Coeficiente & $\mathrm{t}$ & Coeficiente & $t$ & Coeficiente & $\mathrm{t}$ \\
\hline$A D$ & 0,00004 & 0,58 & 0,00012 & $2,71^{* * *}$ & 0,00015 & 1,53 \\
\hline Tam & 0,00336 & $4,23^{\star \star \star}$ & 0,00127 & $2,89^{\star \star \star *}$ & $-0,00303$ & $-2,19^{* *}$ \\
\hline Endiv & $-0,01258$ & $-1,99^{\star *}$ & $-0,00670$ & $-1,93^{*}$ & $-0,01309$ & $-1,27$ \\
\hline Desemp & 0,03307 & 1,22 & 0,01055 & 1,03 & 0,00710 & 0,41 \\
\hline Liquidez & 0,00211 & $4,9^{\star \star \star}$ & 0,00066 & 1,4 & $-0,00206$ & $-2,36^{\star *}$ \\
\hline $\mathrm{Mg}$ & 0,00270 & 1,53 & 0,00175 & $4,06^{\star \star *}$ & 0,00088 & 0,94 \\
\hline Cresc & 0,00410 & 1,37 & 0,00154 & 0,79 & $-0,00010$ & $-0,04$ \\
\hline Alavanc & $-0,00232$ & $-4,23^{\star * *}$ & $-0,00045$ & $-2,54^{\star *}$ & 0,00117 & $1,9^{*}$ \\
\hline Idade & $-0,00021$ & $-2,14^{\star \star}$ & $-0,00006$ & $-1,18$ & $-0,00004$ & $-0,24$ \\
\hline $\mathrm{GC}$ & $-0,00776$ & $-1,74^{*}$ & $-0,00539$ & $-2,77^{\star \star *}$ & $-0,00183$ & $-0,39$ \\
\hline Big4 & $-0,00144$ & $-0,28$ & 0,00215 & 1,02 & $-0,00696$ & $-1,64$ \\
\hline Constante & 0,89491 & $73,26^{\star * *}$ & 0,97608 & $134,07^{\star \star *}$ & 1,11408 & $52,31^{* * *}$ \\
\hline
\end{tabular}

Tanto para análise de correlação, diferença de média e regressão múltipla, os resultados indicaram uma relação positiva entre o tempo na entrega das DFPs e o retorno das ações. Esse resultado também foi corroborado na análise quantílica, para qualquer que seja o nível de quartil (Q10, Q50 ou Q90), desde que considere retornos positivos. Esse resultado contraria o que era esperado pela literatura (Al-Ajmi, 2008; Al- 
Ghanem \& Hegazy, 2011; Cohen \& Leventis, 2013; Habib \& Bhuiyan, 2011; Payne \& Jensen, 2002). Uma possível justificativa para isso é que o tempo na entrega dos resultados do exercício da empresa permite que a empresa proceda com uma melhor revisão e escolhas de métodos contábeis (Skinner, 1994; Watts \& Zimmerman, 1986; Trueman, 1990). Nesse sentido, Lambert, Brazel e Jones (2007) identificaram que maior tempo na entrega das DFPs está associado com maior qualidade dos resultados, o que pode ser captado pelos investidores. Ainda é possível considerar que, diante de maior tempo na entrega das DFPs, o mercado pode antecipar algumas informações, de modo a anular o possível efeito negativo relativo ao próprio tempo.

Dado que a literatura prévia relaciona o maior tempo para publicação das DFPs no mercado como indicativo de baixa qualidade da auditoria e até práticas de gerenciamento de resultados, ao verificar uma relação positiva entre esse tempo o retorno das ações, podemos considerar que muitas informações contábeis são refletidas no mercado antes mesmo da publicação das DFPs, de modo que tais informações permitem ao mercado antecipar os resultados. Essa ideia está de acordo com o que comentavam Chambers e Penman (1984), os quais, ainda colocaram que, quanto mais longo o tempo para divulgação das DFPs, maior a oportunidade de mais informações serem fornecidas por outras fontes e maior o tempo de pesquisa do investidor, destacando aqui o papel dos analistas financeiros.

Ainda, é possível considerar que, enquanto as demonstrações não são divulgadas, os gestores têm a possibilidade de alterar a estratégia de mercado para que os preços das ações e, como consequência, para que o retorno não tenha um mau desempenho. Essa observação vai de encontro com o colocado por Trueman (1990).

Além desses aspectos, tem outro ponto que justifica o resultado obtido nesse estudo, abordado por deHaan, Shevlin e Thornock (2015). Os referidos autores consideram ser possível especular que as empresas, muitas vezes, esperam o mercado acalmar para publicar seus resultados. Isso acontece, geralmente, para evitar reações extremas do mercado, principalmente as negativas. Ao evitar reações extremas, evita-se atrair atenção da mídia, por exemplo, para situações alarmantes, Portanto, as empresas podem atrasar a divulgação de informações para atrair ou evitar a atenção do mercado (deHaan et al., 2015; Johnson \& So, 2018).

Por fim, ainda é possível considerar o fato de que os gestores podem ter preferência em esperar o concorrente divulgar suas respectivas informações contábeis. Isso porque, conforme observaram Gong et al. (2019), a divulgação dos resultados pelas empresas pode ser uma estratégia diante do mercado de capitais, uma vez que a divulgação posterior aos seus concorrentes permite à companhia explorar a discrição dos relatórios de modo a atingir certas metas e assim, apresentarem desempenho relativo superior aos seus concorrentes, de modo a afetar o mercado de capitais.

Com relação a variável tamanho, a análise de correlação indicou relação positiva com retorno, conforme esperado pela literatura (Che, 2018; Nardi \& Nakao, 2009), embora não significante. As análises de diferença de média e regressão apresentaram indícios de que as empresas maiores tendem a ter menor retorno, contrariando a literatura (Eliwa et al., 2016; García et al., 2017; Lugo, 2017; Pornupatham, 2015; Nardi \& Nakao, 2009; Silva et al., 2016; Souza \& Nardi, 2018). Além disso, a regressão quantílica indicou que empresas com os menores retornos apresentam relação positiva com tamanho, mas que, empresas com maiores retornos apresentam relação negativa.

Os resultados de todos os testes apontam para uma relação negativa entre endividamento e retorno das ações, inclusive em qualquer que seja o quartil de retorno, coerente com Lugo (2017) e Nardi e Nakao (2009). Esse resultado indica que o retorno das ações fica afetado quando a empresa tem maior quantidade de dívidas, já que o caixa e equivalentes de caixa ficam comprometidos para este fim (Nardi \& Nakao, 2009).

Assim como observado pelas pesquisas prévias (Chen et al., 2017; Souza \& Nardi, 2018), os resultados indicaram que empresas com maior desempenho apresentam maior retorno, sendo esse resultado indiferente em termos quantílicos. Isso se dá já que boas práticas de mercado e de política interna da empresa revelam a eficiência da firma, medida através dos indicadores de desempenho (Waddock \& Graves, 1997). Sua eficiência é aumentada quando há um melhor desempenho, tendendo a impactar positivamente a rentabilidade do retorno das ações e, consequentemente (Pace, Basso, \& Silva, 2003), atraindo mais investidores.

Com relação à liquidez, os resultados indicaram que empresas com maior liquidez apresentam maior retorno, corroborando a literatura (Souza \& Nardi, 2018), embora as empresas com maiores retornos apresentaram menor liquidez, ao observar a análise quantílica. A liquidez possibilita aos investidores uma análise de curto prazo sobre a situação financeira da empresa, ou seja, quanto maior for sua liquidez, melhor será sua saúde financeira, o que pode justificar impacto positivo nos retornos. Os resultados indicaram que empresas com maior margem apresentam maior retorno, coerente com o apontado pela literatura (Robu \& Robu, 2015; Souza \& Nardi, 2018).

A respeito da relação entre retorno e crescimento da empresa, os resultados indicaram haver uma relação positiva entre as variáveis, corroborando as pesquisas prévias (García et al., 2017; Gomariz \& Ballesta, 2014; Souza \& Nardi, 2018; Silva et al., 2016). Como crescimento está interligado com o desempenho da empresa, quanto maior é o crescimento é de se esperar maior o retorno das ações.

Os resultados sinalizaram que empresas mais alavancadas apresentam menor retorno, divergindo da literatura (Chen et al., 2017; Eliwa et al., 2016; Nardi \& Nakao, 2009). Uma possível explicação para isso é 
que, se a empresa é alavancada, significa que ela se financia através de capital de terceiros de curto prazo, o que faz aumentar sua dívida de curto prazo e, consequentemente, seu passivo circulante, que acaba por impactar no retorno das ações (Nardi \& Nakao, 2009). Nos testes quantílico foi observado que empresas com maiores retornos apresentam maior alavancagem. Possivelmente, ao se alavancar, a empresa incorre em maiores riscos operacionais, de capital e financeiros (Penman, Richardson, \& Tuna, 2007), com isso, o do retorno das ações tende a aumentar.

Com relação a variável Idade, os testes indicaram para uma relação negativa com o retorno das ações, em qualquer que seja o quantil de retorno, o que é contrário ao obtido pela literatura prévia (Arruda et al., 2012; Lugo, 2017; Nardi \& Nakao, 2009; Souza \& Nardi, 2018). Uma possível justificativa para isso é que, na maturação do ciclo de vida da empresa, muitas empresas reduzem suas atividades operacionais, já que não conseguem arcar com os seus custos (Lima, Carvalho, Paulo, \& Girão, 2015), em consequência disso, a rentabilidade de suas ações cai e menos investidores são atraídos.

Para todos os testes utilizados, os resultados indicaram que as empresas listadas nos Níveis Diferenciados de Governança Corporativa da Bovespa apresentam menor retorno. Tais achados são contrários aos obtidos pela literatura prévia (Arruda et al., 2012; Lugo, 2017; Nardi \& Nakao, 2009; Souza \& Nardi, 2018). Por outro lado, há uma linha de estudo que vem observando que as empresas que acabam se listando aos NDGC são aquelas em que se pode observar uma saúde financeira não tão favorável, visto que os efeitos internos na empresa da Governança Corporativa são muito mais visíveis em organizações mais fracas (Ciftci, Tatoglu, Wood, Demirbag, \& Zaim, 2019).

Por fim, os resultados indicaram que empresas auditadas por Big Four tem relação negativa com retorno. Uma possível explicação para isso é que há a ideia de as empresas auditadas pelas Big Four possuem um nível maior de conservadorismo (Lai, 2013) e, como os investidores tendem a ser avessos ao risco, para atrair mais investidores, as empresas com problemas em saúde financeira optam por serem auditadas pelas Big Four, com a intenção de tentar atrair mais investidores.

\subsection{Análises para o custo da dívida}

De modo semelhante à análise para retorno, a relação entre custo da dívida e audit delay foi feita mediante teste de correlação de Spearmam (Tabela 6), teste de diferença de média entre as variáveis explicativas e o custo da dívida (Tabela 7), análise de regressão com dados em painel (Tabela 8), cujos modelos apresentaram problemas de heterocedasticidade, testado pelo teste de Wald, e correlação serial a $10 \%$, testado pelo teste de Wooldridge, mas não houve problemas de multicolineridade, pelo teste de VIF. Por fim, foi realizada a regressão quantílica (Tabela 9).

Tabela 5:

Correlação para custo da dívida

\begin{tabular}{cc}
\hline \multicolumn{2}{c}{ Custo da Dívida } \\
\hline AD & $0,2310^{\star * *}$ \\
Tam & $-0,1462^{\star * *}$ \\
Endiv & $-0,405^{\star * *}$ \\
Desemp & $0,3474^{* * *}$ \\
Risco & $0,1209^{\star * *}$ \\
Liquidez & $-0,1580^{\star * *}$ \\
Mg & $-0,1108^{\star * *}$ \\
Cresc & 0,011 \\
Alavanc & $-0,0186$ \\
Idade & $0,0925^{\star * *}$ \\
Tang & $-0,0041$ \\
Volat & $0,1713^{* * *}$ \\
\hline Sendo &
\end{tabular}

Tabela 6:

Diferença de média para custo da dívida

\begin{tabular}{|c|c|c|c|}
\hline & Q1 & Q4 & $z$ \\
\hline$A D$ & 0,1433133 & 0,3362591 & $-17,874^{\star * *}$ \\
\hline Tam & 0,3353654 & 0,1605064 & $9,752^{\star \star *}$ \\
\hline Endiv & 0,5536129 & 0,0919344 & $25,695^{\star \star \star}$ \\
\hline Desemp & 0,1661619 & 0,3381364 & $-20,776^{\star * *}$ \\
\hline Risco & 0,1935315 & 0,3706508 & $-9,658^{* * *}$ \\
\hline Liquidez & 0,3561193 & 0,2111116 & $11,504^{\star \star \star}$ \\
\hline $\mathrm{Mg}$ & 0,3293763 & 0,1934615 & $8,076^{\star * *}$ \\
\hline Cresc & 0,2884815 & 0,250575 & $-0,492^{*}$ \\
\hline Alavanc & 0,3330961 & 0,2118693 & $0,974^{\star *}$ \\
\hline Idade & 0,1686345 & 0,2081375 & $-7,812^{\star * *}$ \\
\hline GC & 0,2642249 & 0,1879587 & $11,104^{\star * *}$ \\
\hline Big4 & 0,3232336 & 0,1843446 & $9,081^{\star * *}$ \\
\hline Tang & 0,1858942 & 0,2389545 & $-2,891^{* * *}$ \\
\hline Volat & 0,1702752 & 0,3472415 & $-10,616^{\star \star \star}$ \\
\hline
\end{tabular}

Os resultados indicaram que há uma relação positiva e significante entre maior tempo para entrega das DFPs e o custo da dívida, coerente com a literatura (Al-Ghanem \& Hegazy, 2011; Cohen \& Leventis, 2013; Habib \& Bhuiyan, 2011). Uma possível justificativa para isso é que um maior audit delay fundamenta a ideia de que há problemas nas DFPs da empresa (Pereira \& Costa, 2012). Chan, Luo e Mo (2015) sugerem que maior tempo na entrega das DFPs está associado com maior risco e complexidade de auditoria, sugerindo necessidade de grandes acordos entre a auditoria e a administração das empresas para alinhamento das normas contábeis. Além disso, verificaram que maior audit delay hoje ocasiona em ressurgimento de problemas nas DFPs em anos subsequentes. Tais aspectos podem ser observado pelos bancos como empresas de maior risco, justificando a relação positiva com o custo da dívida. 
Tabela 7:

Análise de regressão para custo da dívida

\begin{tabular}{|c|c|c|}
\hline Variáveis & Coeficiente & $\mathbf{z}$ \\
\hline$A D$ & 0,0015184 & 1,99 ** \\
\hline Tam & $-0,0373885$ & $-0,47$ \\
\hline Endiv & $-1,645035$ & $-3,33^{\star * *}$ \\
\hline Desemp & 0,4272765 & 1,11 \\
\hline Risco & 0,6329121 & $2,46^{\star *}$ \\
\hline Liquidez & $-0,0185466$ & $-1,62$ \\
\hline $\mathrm{Mg}$ & $-0,0015959$ & $-1,06$ \\
\hline Cresc & 0,083422 & $2,32^{* *}$ \\
\hline Alavanc & $-0,0040491$ & $-2,45^{\star *}$ \\
\hline Idade & 0,0472026 & $4,65^{\star \star *}$ \\
\hline GC & $-0,0677569$ & $-2,35^{\star *}$ \\
\hline Big4 & 0,0057824 & 0,21 \\
\hline Tang & 0,6244295 & $3,11^{\star * *}$ \\
\hline Volat & 5,374908 & $2,05^{\text {** }}$ \\
\hline $\mathrm{F}$ & \multicolumn{2}{|c|}{$3,31^{* * *}$} \\
\hline $\mathrm{R}^{2}$ & \multicolumn{2}{|c|}{7,78} \\
\hline Breusch and Pagan Lagrangian & \multicolumn{2}{|c|}{$1443,08^{* * *}$} \\
\hline Teste F de Chow & \multicolumn{2}{|c|}{$29,89^{* * *}$} \\
\hline Teste de Hausman & \multicolumn{2}{|c|}{$110,88^{\star * \star}$} \\
\hline Teste de Wald & \multicolumn{2}{|c|}{$3.7 \mathrm{e}+07^{\star \star \star}$} \\
\hline VIF & \multicolumn{2}{|c|}{1,32} \\
\hline Teste de Wooldridge & \multicolumn{2}{|c|}{$3,145^{*}$} \\
\hline
\end{tabular}

Ainda, para manterem os recursos emprestados em certa empresa, os bancos podem exigir atualizações frequentes das informações financeiras, de modo que a não obtenção oportuna dessas informações pode levar a deterioração dos termos da dívida. Essa ideia está alinhada com o observado por Osma, Gomez-Conde e Heras (2018), ou seja, de que os bancos são mais sensíveis a redução no valor da empresa do que a aumentos, por isso há um nível de monitoramento temporal da saúde financeira maior. Além disso, consideram que as empresas com divulgação mais oportuna e informativas tem menos probabilidade de reter más notícias relevantes aos credores, podendo assim obterem melhores termos de crédito. O que está alinhado aos achados desse estudo.

Tabela 8:

Análise quantílica para custo da dívida e AD

\begin{tabular}{|c|c|c|c|c|c|c|}
\hline & \multicolumn{2}{|c|}{ Q10 } & \multicolumn{2}{|c|}{ Q50 } & \multicolumn{2}{|c|}{ Q90 } \\
\hline & Coeficiente & $t$ & Coeficiente & $\mathbf{t}$ & Coeficiente & $\mathbf{T}$ \\
\hline$A D$ & 0,00011 & $1,97^{* *}$ & 0,00094 & $7,04^{* * *}$ & 0,00137 & $3,67^{* * *}$ \\
\hline Tam & 0,00007 & 0,13 & $-0,00111$ & $-1,4$ & $-0,00405$ & $-0,96$ \\
\hline Endiv & $-0,07163$ & $-9,11^{* * *}$ & $-0,24604$ & $-18,3^{\star \star *}$ & $-0,92897$ & $-11,49^{\star * *}$ \\
\hline Desemp & 0,23711 & $9,07^{* \star *}$ & 0,43868 & $7,06^{\star * *}$ & 1,17836 & $3,72^{\star * \star}$ \\
\hline Risco & 0,02208 & $5,85^{\star \star \star}$ & 0,13349 & $10,52^{\star \star \star}$ & 0,70842 & $7,36^{\star * \star}$ \\
\hline Liquidez & $-0,00024$ & $-0,33$ & 0,00224 & $1,74^{*}$ & 0,03631 & $3,15^{\star * \star}$ \\
\hline $\mathrm{Mg}$ & $-0,00094$ & $-1,11$ & 0,00003 & 0,02 & 0,00116 & 0,13 \\
\hline Cresc & $-0,00184$ & $-1,06$ & $-0,00127$ & $-0,39$ & 0,00347 & 0,28 \\
\hline Alavanc & 0,00059 & $1,95^{\star}$ & 0,00127 & $3,3^{* * *}$ & $-0,00156$ & $-1,22$ \\
\hline Idade & 0,00009 & $1,77^{*}$ & $-0,00006$ & $-0,51$ & 0,0005 & 1,33 \\
\hline GC & $-0,00379$ & $-3,51^{* * *}$ & 0,00032 & 0,11 & 0,03496 & $2,45^{\star *}$ \\
\hline Big4 & 0,00237 & 1,22 & $-0,0071$ & $-1,87^{*}$ & $-0,021$ & $-1,42$ \\
\hline Tang & 0,01092 & $4,75^{\star \star \star}$ & 0,02336 & $3,92^{\star \star *}$ & 0,11135 & $4,26^{\star \star \star}$ \\
\hline Volat & 0,06237 & 1,47 & 0,10586 & 1,17 & 0,91202 & $1,8^{*}$ \\
\hline Constante & 0,01228 & 1,33 & 0,01995 & 1,59 & $-0,05577$ & $-0,96$ \\
\hline
\end{tabular}

Com relação ao tamanho, embora o resultado da regressão não tenha sido significante, é possível observar que há indícios de que as empresas maiores apresentam menor custo da dívida. Esse resultado é coerente com o esperado (Eliwa et al., 2016; García et al., 2017; Lugo, 2017; Pornupatham, 2015; Nardi \& Nakao, 2009; Silva et al., 2016; Souza \& Nardi, 2018), possivelmente pelo fato de que a quantidade de ativo que essas empresas conseguem oferecer em garantia aos bancos é maior, quando da obtenção de empréstimos, conseguindo negociar melhores custos da dívida (Valle, 2007). 
Os resultados indicaram que empresas com maior endividamento apresentam menor custo da dívida, o que está de acordo com o encontrado por Lugo (2017) e Nardi e Nakao (2009). Uma das hipóteses a ser levantada é que a rentabilidade das atividades operacionais da empresa é capaz de suprir as necessidades do pagamento das dívidas, já que o endividamento ótimo seria definido pelo menor custo total (Kayo, Teh, \& Basso, 2006).

Os achados apontaram para uma relação positiva entre o desempenho das empresas e o custo da dívida, independentemente do nível quantílico de custo da dívida, resultado contrário ao obtido por Lugo (2017) e Souza e Nardi (2018). Isso pode ser explicado pelo fato das empresas com maiores índices de desempenho necessitarem de mais recursos para se desenvolverem, acarretando em maior custo da dívida.

Verificou-se ainda uma relação positiva entre risco e o custo da dívida, como esperado por Pornupatham (2015) e Souza e Nardi (2018). Geralmente, os bancos utilizam das demonstrações auditadas para analisar a possível aptidão da empresa ao risco operacional antes de realizarem algum tipo de empréstimo, com a finalidade de avaliar o quanto arriscada a organização é. No caso dos bancos, por exemplo, quanto mais arriscada é a firma, maiores são os juros cobrados nos empréstimos.

Com relação a variável liquidez, os indícios obtidos foram de que empresas mais líquidas tendem a ter menor custo da dívida, devido ao fato de a tendência de empresas mais líquidas serem mais bem vistas pelos bancos, reduzindo o custo da dívida (Hopp \& Leite, 1989). No entanto, pela análise quantílica, observouse que empresas com maiores custos da dívida apresentam maior liquidez, o que pode estar relacionado ao fato de que o pagamento de uma dívida pode reduzir o índice de liquidez da empresa, então, para aumentar novamente o índice de liquidez, é necessário contrair empréstimos, o que levaria a um aumento do custo da dívida (Hopp \& Leite, 1989).

A respeito da relação entre o custo da dívida e a margem, os resultados indicaram haver uma relação negativa entre as variáveis. Isso pode ser explicado devido ao fato de empresas com maiores margens possuírem maior credibilidade perante aos credores, ou seja, evitam custos elevados de financiamento externo (Silva \& Brito, 2005).

No geral, os resultados indicaram haver uma relação positiva entre o crescimento das empresas e o custo da dívida, contrário ao encontrado por García et al. (2017), Gomariz e Ballesta (2014), Souza e Nardi (2018) e Silva et al. (2016). Isso pode ser explicado já que a tendência ao crescimento da empresa pode estar relacionada, além de outros fatores, à necessidade de tomar um empréstimo para financiar suas atividades, aumentando seu custo da dívida. No entanto, o teste de diferença de média apontou para uma relação negativa entre crescimento e custo da dívida, o que pode estar relacionado ao fato de a empresa estar na fase de crescimento dentro do seu ciclo de vida (Kayo, Kimura, Martin, \& Nakamura, 2006), não sendo necessário o aporte de capital de terceiros para se financiar.

Com relação a variável alavancagem, os resultados apontaram que as empresas mais alavancadas apresentam menor custo da dívida, contrariando a literatura (Eliwa et al., 2016; Nardi \& Nakao, 2009). Complementarmente, observou-se que as empresas com menores custo da dívida, observando a divisão quantílica, apresentam maior alavancagem, enquanto que as empresas com maiores custos da dívida apresentaram relação negativa com alavancagem. Uma hipótese a ser levantada a cerca deste resultado é que pode haver a manipulação momentânea dos dados e resultados em empresas mais alavancadas (ludícibus \& Lopes, 2004; Morsfield \& Tan, 2006; Schipper, 1989) para conseguir financiamentos a baixos custos, fazendo com que seu custo da dívida reduza e que cláusulas contratuais de dívidas não sejam violadas (Morsfield \& Tan, 2006).

No geral, os resultados indicaram que empresas de maior idade possuem maior custo da dívida, coerente com Lugo (2017) e Nardi e Nakao(2009). Possivelmente, as empresas com maior idade tendem a não estar na fase de crescimento de suas operações, sendo necessários alguns investimentos para manter algumas atividades (Kayo et al., 2006; Lima et al., 2015).

Entre as variáveis governança corporativa e custo da dívida, os resultados indicaram que há uma relação negativa e significante entre elas. No entanto, é possível observar que as empresas com maiores custo da dívida médio (Q90) apresentam relação positiva com empresas listadas nesses níveis, o que está de acordo com pesquisas recentes que identificaram que as empresas mais arriscadas estão se alistando nos NDGC para tentar mostrar maior segurança ao mercado (Ciftci et al., 2019), já que está implícito que na Governança Corporativa se desenvolve processos com maior visibilidade e transparência para tomada de decisão (Bertucci, Bernardes, \& Brandão, 2006).

Os resultados indicaram ainda que as empresas auditadas por Big Four apresentam menor custo da dívida, coerente Arruda et al. (2012) e Souza e Nardi (2018), o que pode ser explicados pelo fato de as DFP`s acompanhadas por auditores independentes tendem a fornecer mais credibilidade, fidedignidade e transparência na qualidade das informações. No que se refere a relação entre custo da dívida e tangibilidade, foi observada uma relação positiva, coerente com Nardi e Nakao (2009), Titman e Wessels (1988). Esse resultado pode ser explicado pelo fato de a tangibilidade dos ativos ser utilizada em garantias de contratos de dívidas (Titman \& Wessels, 1988; Valle, 2007), assim, as taxas de juros em torno desse ativo, teoricamente, não são aumentadas (Nardi \& Nakao, 2009) e os prazos podem ser estendidos.

Por fim, os testes indicaram haver uma relação positiva entre volatilidade e custo da dívida, coeso com a literatura de Lei et al. (2017) e Nardi e Nakao (2009). A volatilidade mede a oscilação do fluxo de caixa 
de uma empresa, portanto, relacionada com o risco da empresa. Portanto, quanto mais volátil e arriscada são os resultados apresentados da empresa, maiores são seus custos da dívida.

\section{Considerações Finais}

Em um mercado eficiente, os investidores buscam continuamente alternativas que the proporcionem o máximo de retorno possível com o mínimo de risco (Robu \& Robu, 2015). Dessa forma, é possível afirmar que as informações contábeis da empresa possuem grande influência na tomada de decisão dos usuários da informação. Diante disso, o objetivo desse trabalho foi analisar a influência na confiabilidade das informações contábeis para seus usuários diante do audit delay, ou seja, verificar se há variações nos retornos das ações e nos custos de capital de acordo com o tempo que leva para as DFPs serem divulgadas ao mercado de capitais, uma vez que qualquer mudança nos relatórios afeta diretamente os principais usuários da informação para o mercado de capitais, como investidores e instituições bancárias. Para isso, foi utilizado uma amostra de empresas listadas na B3 e CVM, compreendendo os anos de 2010 a 2017.

De modo geral, os resultados indicaram para uma relação positiva entre audit delay e o retorno das ações e o custo da dívida. Com relação ao retorno, essa relação positiva possivelmente pode ser decorrente do fato de que os gestores podem segurar a informação por mais algum tempo para evitar alguma flutuação do mercado, ou mesmo esperar que a reação do mercado à informação do tempo na entrega das DFPs tenha ocorrido em um período anterior à divulgação. Além disso, a relação pode ser explicada pelo fato de haver uma maior revisão da informação contábil, ocasionando em resultados de maior qualidade.

No entanto, os resultados positivos para o custo da dívida indicam que as instituições bancárias podem reagir diferentemente dos investidores diante de maior tempo na entrega das DFPs, ou seja, percebendo maior risco e complexidade nos processos de auditoria, consequentemente, maior no risco da empresa.

A pesquisa evidencia o comportamento distinto de reação diante do atraso da entrega das DFPs pelas principais fontes de recursos das empresas. Esse resultado é importante para as empresas compreenderem que maior tempo de divulgação das informações contábeis precisa ser ponderado diante de seu interesse em definir sua estrutura de captação de recurso, de modo a evitar elevar os custos desses financiamentos. Consequentemente, os resultados sugerem ainda a possibilidade de que o benefício do não atraso das DFPs possa ser em termos de redução no custo de captação de recursos por instituições bancárias.

Dessa forma, o estudo contribui para a pesquisa acadêmica ao analisar relações ainda não evidenciadas pelos estudos nacionais, embora relativamente tratado pelas pesquisas internacionais, bem como evidencia consequências a que a empresa está exposta diante do tempo na entrega das DFPs, compreendendo que o efeito negativo se dá mais sob o ponto de vista de bancos em relação aos investidores.

Cabe destacar que as pesquisas poderiam avançar no estudo, considerando a relação entre o custo da dívida e o tempo de divulgação das DFPs em períodos defasados. Também poderiam focar em analisar a possibilidade de inter-relação entre as variáveis, por meio do uso de análise de simultaneidade. E ainda, fazer um comparativo entre mercados baseados em sistema common law e civil law, para analisar se o comportamento de captação de recursos desses mercados pode apresentar relação distinta entre os custos de captação e tempo de divulgação das DFPs.

\section{Referências}

Abidin, S. \& Ahmad-Zaluki, N. A. (2012). Auditor industry specialism and reporting timeliness. ProcediaSocial and Behavioral Sciences, 65(3), 873-878. https://doi.org/10.1016/j.sbspro.2012.11.213

Ahmad, M., Mohamed, H., \& Nelson, S. P. (2016). The association between industry specialist auditor and financial reporting timeliness - post MFRS period. Procedia - Social and Behavioral Sciences, 219, 55-62. https://doi.org/10.1016/i.sbspro.2016.04.036

Al-Ajmi, J. (2008). Audit and reporting delays: Evidence from an emerging market. Advances in Accounting, incorporating Advances in International Accounting, 24, 217-226. https://doi.org/10.1016/i.adiac.2008.08.002

Al-Ghanem, W. \& Hegazy, M. (2011). An empirical analysis of audit delays and timeliness of corporate financial reporting in Kuwait. Eurasian Business Review, 1, 73-90. https://doi.org/ 10.14208/BF03353799

Alzoubi, E. S. S. (2018). Audit quality, debt financing, and earnings management: Evidence from Jordan. Journal of International Accounting, Auditing and Taxation, 30, 69-84. https://doi.org/10.1016/j.intaccaudtax.2017.12.001

Akerlof, G. (1970). The Markets For "Lemons": Quality Uncertainly and The Market Mechanism. The Quarterly Journal of Economics, 84, 488-500. http://www.jstor.org/stable/1879431 
Alkhatib, K. \& Marji, Q. (2012). Audit reports timeliness: Empirical evidence from Jordan. Procedia - Social and Behavioral Sciences, 62, 1342-1349. https://doi.org/10.1016/j.sbspro.2012.09.229

Arruda, M. P., Sousa, R. A. M., Pena, T. J. S., Paulo, I. I. S. L. M., \& Paulo, E. (2012). Repercussão do Anúncio dos Pareceres de Auditoria no Preço das Ações das Companhias Abertas Brasileiras. Revista da Faculdade de Administração e Economia, 4, 230-250. http://dx.doi.org/10.15603/2176-9583/refae.v4n1p230$\underline{250}$

Artiach, T., Lee, D., Nelson, D., \& Walker, J. (2010). The determinants of corporate sustainability performance. Accounting \& Finance, 50(1), 31-51. https://doi.org/10.1111/.1467-629X.2009.00315.x

Barcellos, L. P., Costa Júnior, J. V., \& Laurence, L. C. (2014). Determinantes do Prazo de Divulgação das Demonstrações Contábeis das Companhias Não Financeiras Listadas na Bovespa. Revista de Contabilidade e Organizações, 8(20), 84-100, 2014. https://doi.org/10.11606/rco.v8i20.69265

Barros, C. M. E., Silva, P Y. C., \& Voese, S. B. (2015). Relação entre o Custo da Dívida de Financiamentos e Governança Corporativa no Brasil. Contabilidade, Gestão e Governança, 18(2), 7-26. https://www.revistacgg.org/contabil/article/view/641/pdf

Bastos, D. D., Nakamura, W. T., David, M., \& Rotta, U. A. S. (2009). A relação entre o retorno das ações e as métricas de desempenho: evidências empíricas para as companhias abertas no Brasil. Revista de Gestão USP, 16, 65-79. https://anaiscbc.emnuvens.com.br/anais/article/view/1312/1312

Beaver, W. H. (1968). The information content of annual earnings announcements. Journal of Accounting Research, 6, 67-92. https://doi.org/10.2307/2490070

Beiruth, A. X., Brugni, T. V., Fávero, L. P., \& Góes, A. O. S. (2014). Níveis diferenciados de governança corporativa e disclosure timeliness: um estudo exploratório no mercado brasileiro. Revista de Gestão, Finanças e Contabilidade, 4(1), 77-89. https://doi.org/10.18028/rgfc.v4i1.565

Bertucci, J. L. O., Bernardes, P., \& Brandão, M. M. (2006). Políticas e práticas de governança corporativa em empresas brasileiras de capital aberto. Revista de Administração, 41(2), 183-196.

http://www.spell.org.br/documentos/ver/16927/politicas-e-praticas-de-governanca-corporativa-em-empresasbrasileiras-de-capital-aberto/i/pt-br

Bonsón-Ponte, E., Escobar-Rodríguez, T., \& Borrero-Domínguez, C.(2008). Empirical analysis of delays in the signing of auditing reports in Spain. International Journal of Auditing, 12(2), 129-140.

https://doi.org/10.1111/j.1099-1123.2008.00375.x

Boone, J. P., Khurana, I. K., \& Raman, K. K. (2010). Do the Big 4 and the Second-tier firms provide audits of similar quality? Journal of Accounting Policy, 29(4), 330-352.

https://doi.org/10.1016/j.jaccpubpol.2010.06.007

Brooks, C. (2002). Introductory econometrics for finance. Cambridge: Cambridge University Press.

Chambers, A. E. \& Penman, S. H. (1984). Timeliness of reporting and stock price reaction to earnings announcements. Journal of Accounting Research, 22(1), 21-47. https://doi.org/10.2307/2490700

CHAN, K. H.; LUO, V. W.; LO, P. L. L. Determinants and implications of long audit reporting lags: evidence from China. Accounting and Business Research, n.46, p. 154-166, 2015. DOI: https://doi.org/10.1080/00014788.2015.1039475

CHE, L. Investor types and stock return volatility. Journal of Empirical Finance, n.47, p. 139-161, 2018. DOI: https://doi.org/10.1016/i.jempfin.2018.03.005

Chen, C., Kim, J. B., \& Yao, L. (2017). Earnings smoothing: Does it exacerbate or constrain stock price crash risk? Journal of Corporate Finance, 42, 36-54. https://doi.org/10.1016/i.jcorpfin.2016.11.004

Chen, C. J. P., Chen, S., \& Su, X. (2001). Is accounting information value-relevant in the emerging Chinese stock market? Journal of International Accounting, Auditing \& Taxation, 10(1), 1-22.

https://doi.org/10.1016/S1061-9518(01)00033-7 
Chung, H., Judge, W. Q., \& Li, Y. (2015). Voluntary disclosure, excess executive compensation, and firm value. Journal of Corporate Finance, 32, 64-90. https://doi.org/10.1016/j.jcorpfin.2015.04.001

Ciftci, I., Tatoglu, E., Wood, G., Demirbag, M., \& Zaim, S. (2019). Corporate governance and firm performance in emerging markets: Evidence from Turkey. International Business Review, 28(1), 90-103. https://doi.org/10.1016/j.ibusrev.2018.08.004

Cohen, S. \& Leventis, S. (2013). Effects of municipal, auditing and political factors on audit delay. Accounting Forum, 37(1), 40-53. https://doi.org/10.1016/i.accfor.2012.04.002

CPC 00 - Estrutura Conceitual para Elaboração e Divulgação de Relatório Contábil-Financeiro. Disponível em: http://www.cpc.org.br/CPC/Documentos-Emitidos/Pronunciamentos/Pronunciamento?ld=80. Acesso em: 01 ago. 2017.

Dantas, J. A. \& Medeiros, O. R. (2015). Determinantes de Qualidade da Auditoria Independente em Bancos. Revista Contabilidade \& Finanças, 26(67), 43-56. https://doi.org/10.1590/1808-057x201400030

deHann, E., Shevlin, T., \& Thornock, J. (2015). Market (In)Attention and the Strategic Scheduling and Timing of Earnings Announcements. Journal of Accounting and Economics, 60(1), 36-55.

https://doi.org/10.1016/j.jacceco.2015.03.003

Dong, B., Robinson, D., \& Xu, L. E. (2018). Auditor-client geographic proximity and audit report timeliness. Advances in Accounting, 40, 11-19. https://doi.org/10.1016/i.adiac.2017.12.001

Dopuch, N., Holthausen, R., \& Leftwich, R. (1986). Abnormal Stock Returns associated with media disclosures of "subject" qualified audit opinion. Journal of Accounting and Economics, 8(2), 93-117. https://doi.org/10.1016/0165-4101(86)90013-3

Easley, D. \& O'hara M. (2005). Information and the cost of capital. The Journal of Finance, 59(4), 15531583. https://doi.org/10.1111/j.1540-6261.2004.00672.x

Eliwa, Y., Haslam, J., \& Abraham, S. (2016). The association between earnings quality and the cost of equity capital: Evidence from the UK. International Review of Financial Analysis, 48, 125-139.

https://doi.org/10.1016/j.irfa.2016.09.012

Firmino, J. E., Damascena, L. G., \& Paulo, E. (2010). Qualidade da Auditoria no Brasil: um estudo sobre a atuação das auditorias independentes denominadas Big Four. Sociedade, Contabilidade e Gestão, n.5, p. 40-50, 2010. DOI: https://doi.org/10.21446/scg ufri.v5i3.13215

García, M. D. P. R., Alejandro, K. A. C., Sáenz, A. B. M., \& Sánchez, H. H. G. (2017). Does an IFRS adoption increase value relevance and earnings timeliness in Latin America? Emerging Markets Review, 30, 155-168. https://doi.org/10.1016/j.ememar.2016.11.001

Gomariz, M. F. C. \& Ballesta, J. P. S. (2014). Financial reporting quality, debt maturity and investment efficiency. Journal of Banking \& Finance, 40, 494-506. https://doi.org/10.1016/j.jbankfin.2013.07.013

Gong, G., Li, L. Y., \& Yin, H. (2019). Relative Performance Evaluation and the Timing of Earnings Release. Journal of Accounting and Economics, 67(2-3), 358-386. https://doi.org/10.1016/j.jacceco.2019.03.002

Habib, A. \& Bhuiyan, M. B. U. (2011). Audit firm industry specialization and the audit report lag. Journal of International Accounting, Auditing and Taxation, 20(1), 32-44.

https://doi.org/10.1016/i.intaccaudtax.2010.12.004

Healy, P. M. \& Palepu, K. G. (2001). Information asymmetry, corporate disclosure, and the capital markets: A review of the empirical disclosure literature. Journal of Accounting and Economics, 31(1-3), 405-440. https://doi.org/10.1016/S0165-4101(01)00018-0

Healy, P. M., \& Wahlen, J. M. (1999). A review of the earnings management literature and its implications for standard setting. Accounting Horizons, 13, 365-383. https://doi.org/10.2308/acch.1999.13.4.365

Hohenfels, D. (2016). Auditor Tenure and Perceive Earnings Quality. International Journal of Auditing, 20(3), 224-238. https://doi.org/10.1111/ijau.12069 
Hopp, J. C. \& Leite, H. P. (1989). O mito da liquidez. Revista de Administração de empresas, 29, 63-69. http://dx.doi.org/10.1590/S0034-75901989000400006

ludícibus, S. \& Lopes, A. B. (2014). Teoria Avançada da Contabilidade. São Paulo: Atlas.

Jensen, M. \& Meckling, W. H. (1976). Theory of the firm: managerial behavior, agency costs and ownership structure. Journal of Financial Economics, 3(4), 305-360. https://doi.org/10.1016/0304-405X(76)90026-X

Johnson, T. L. \& So, E. C. (2018). Time Will Tell: Information in the Timing of Scheduled Earnings News. Journal of Financial and Quantitative Analysis, 53(6), 2431-2464. https://doi.org/10.1017/S0022109018000492

Kayo, E. K. \& Famá, R. (2004). A estrutura de capital e o risco das empresas tangível-intensivas e intangível-intensivas. Revista de Administração da USP, 39, 164- 176.

https://pdfs.semanticscholar.org/9867/713e1dd808eaefc87e19386f46edac31e74e.pdf

Kayo, E. K., Kimura, H., Martin, D. M. L., \& Nakamura, W. T. (2006). Ativos Intangíveis, Ciclo de Vida e Criação de Valor. Revista de Administração Contemporânea, 10(3), 73-90. http://dx.doi.org/10.1590/S1415$\underline{65552006000300005}$

Kayo, E. K., Teh, C. C., \& Basso, L. F. C. (2006). Ativos intangíveis e estrutura de capital: a influência das marcas e patentes sobre o endividamento. Revista de Administração, 41(2), 158-168. http://rausp.usp.br/wpcontent/uploads/files/V4102158.pdf

Kim, J. B., Song, B. Y., \& Tsui, J. S. L. (2013). Auditor Size, Tenure, and Bank Loan Pricing. Review of Quantitative Finance and Accounting, 40, 75-99. https://doi.org/10.1007/s11156-011-0270-z

Kirch, G., Lima, J. B. N., \& Terra, P. R. S. (2012). Determinantes da defasagem na divulgação das demonstrações contábeis das companhias abertas brasileiras. Revista Contabilidade \& Finanças, 23(60), 173-186. https://doi.org/10.1590/S1519-70772012000300003

Knechel, W. R. \& Payne, J. L. (2001). Additional Evidence on Audit Report Lag. Auditing: A Journal of Practice \& Theory, 20(1), 137-146. https://doi.org/10.2308/aud.2001.20.1.137

Lai, K. W. (2013). Audit Reporting of Big 4 Versus Non-Big 4 Auditors: The Case Of Ex-Andersen Clients. The International Journal of Accounting, 48(4), 495-524. https://doi.org/10.1016/.i.intacc.2013.10.001

Lambert, T. A., Brazel, J. F., \& Jones, K. L. (2007). Unintended Consequences of Accelerated Filings: Do Changes in Audit Delay Lead to Changes in Earnings Quality? SSRN Eletronic Journal. https://doi.org/10.2139/ssrn.963402

Lambert, R., Leuz, C., \& Verrecchia, R. E. (2007). Accounting information, disclosure and the cost of capital. Journal of Accounting Research, 45, 385-420. https://doi.org/10.1111/j.1475-679X.2007.00238.x

Lei, Q., Wang, X. W., \& Yan, Z. (2017). Volatility Spread and Stock Market Response to Earnings Announcements. Journal of Banking and Finance, 119, 1-47. https://doi.org/10.1016/j.jbankfin.2017.04.002

Lima, A. S., Carvalho, E. V. A., Paulo, E., \& Girão, L. F. A. P. (2015). Estágios do Ciclo de Vida e Qualidade das Informações Contábeis. Revista de Administração Contemporânea, 19(3), 398-418.

http://dx.doi.org/10.1590/1982-7849rac20151711

Lima, G. A. S. F. (2009). Nível de evidenciação x custo da dívida das empresas brasileiras. Revista Contabilidade \& Finanças, 20(49), 95-108. http://dx.doi.org/10.1590/S1519-70772009000100007

Linn, E. \& Diehl, K (2005). Financial restatements: causes, consequences, and corrections. Strategic Finance, 3, 34-39.

Lugo, S. (2017). Insider ownership and the cost of debt capital: Evidence from bank loans. International Review of Financial Analysis, 63, 357-368. https://doi.org/10.1016/j.irfa.2016.12.007

Morsfield, S. G. \& Tan, C. E. L. (2006). Do venture capitalists influence the decision to manage earnings in initial public offerings? Accounting Review, 81(5), 1119-1150. https://www.jstor.org/stable/4093100 
Nardi, P. C. C., Amadi, A. F., \& Silva, R. L. M. (2019). Análise da relação entre as características qualitativas da informação contábil e o audit delay. Advances in Scientific and Apllied Accounting, 12(3), 101-119. http://dx.doi.org/10.14392/asaa.2019120306

Nardi, P. C. C. \& Nakao, S. H. (2009). Gerenciamento de resultados e a relação com o custo da dívida das empresas brasileiras abertas. Revista Contabilidade \& Finanças, 20(51), 77-100. http://dx.doi.org/10.1590/S1519-70772009000300006

Ng, P. P. H. \& Tai, B. Y. K. (1994). An empirical examination of the determinants of audit delay in Hong Kong. British Accounting Review, 26(1), 43-59. https://doi.org/10.1006/bare.1994.1005

Niyama, J. K. (2005). Contabilidade internacional. São Paulo: Atlas, 2005.

Oliveira, L., Cunha, P. R., Santos, V., Faveri, D. B., \& Junior, M. M. R. (2015). Relação entre as Características do Comitê de Auditoria e o Atraso da Emissão do Relatório da Auditoria Independente (Audit Delay). Contabilidade, Gestão e Governança, 18, 47-65.

http://www.spell.org.br/documentos/ver/38296/relacao-entre-as-caracteristicas-do-comite-de-auditoria-e-oatraso-da-emissao-do-relatorio-da-auditoria-independente--audit-delay-li/pt-br

Osma, B. G., Gomez-Conde, J., \& Heras, E. (2018). Debt pressure and interactive use of control systems: Effects on cost of debt. Management Accounting Research, 40, 27-46.

https://doi.org/10.1016/j.mar.2017.10.001

Pace, E. S. U., Basso, L. F. C., \& Silva, M. A. (2003). Indicadores de Desempenho como Direcionadores de Valor. Revista de Administração Contemporânea, 7(1), 37-65. http://dx.doi.org/10.1590/S1415$\underline{65552003000100003}$

Palmrose, Z. V. (1986). Audit Fees and Auditor Size: Further Evidence. Journal of Accounting Research, 24(1), 97-110. http://dx.doi.org/10.2307/2490806

Payne, J. L. \& Jensen, K. L. (2002). An examination of municipal audit delay. Journal of Accounting and Public Policy, 21(1), 1-29. https://doi.org/10.1016/S0278-4254(02)00035-2

Penman, S. H., Richardson, S. A., \& Tuna, I (2007). The Book-to-Price Effect in Stock Returns: Accounting for Leverage. Journal of Accounting Research, 45(2), 427-467. https://www.jstor.org/stable/4622038

Pereira, A. N. \& Costa, F. M. (2012). Determinantes do Atraso em Auditoria Externa (Audit Delay) Em Companhias Brasileiras. Anais do EnANPAD, Rio de Janeiro, RJ, Brasil, XXXVI.

Perobelli, F. F. C. \& Famá, R. (2003). Fatores determinantes da estrutura de capital para empresas latinoamericanas. Revista de Administração Contemporânea, 7(1), 9-35. https://doi.org/10.1590/S1415$\underline{65552003000100002}$

Pevzner, M., Xie, F., \& Xin, X. (2015). When firms talk, do investors listen? The role of trust in stock market reactions to corporate earnings announcements. Journal of Financial Economics, 117(1), 190-223. https://doi.org/10.1016/i.jfineco.2013.08.004

Pornupatham, T. V. S. (2015). Do audit opinions reflect earnings persistence? Managerial Auditing Journal, 30(3), 244-276. https://doi.org/10.1108/MAJ-12-2013-0973

Robu, M. A. \& Robu, I. B. (2015). The influence of the audit report on the relevance of accounting information reported by listed Romanian companies. Procedia Economics and Finance, 20, 562-570. https://doi.org/10.1016/S2212-5671(15)00109-4

Rocha, I., Pereira, A. M., Bezerra, F. A., \& Nascimento, S. (2012). Análise da Produção Científica sobre Teoria da Agência e Assimetria de Informação. REGE - Revista de Gestão, 19, 329-342. https://doi.org/10.5700/rege466

Sharma, D. S., Tanyi, P. N. \& Litt, B. A. (2017). Costs of Mandatory Periodic Audit Partner Rotation: Evidence from Audit Fees and Audit Timeliness. Auditing: a journal of a practice \& theory, 36, 129-149. https://doi.org/10.2308/ajpt-51515

Schipper, K. (1989). Commentary: Earnings Management. Accounting Horizons, 3, 91-102, 1989. 
Silva, J. C. G. \& Brito, R. D. (2005). Testando as Previsões de Trade-off e Pecking Order sobre Dividendos e Dívida no Brasil. Estudos Econômicos, 35(1), 37-79. http://dx.doi.org/10.1590/S0101-41612005000100002

Silva, R. L M. \& Nardi, P. C. C. (2014). Demonstrações Contábeis no Brasil após adoção do CPC 13: reação do mercado de ações. Advances in Scientific and Applied Accounting, 3, 362-385.

http://dx.doi.org/10.14392/asaa.2014070303

Silva, R. L M. \& Nardi, P. C. C. (2017). Full adoption of IFRSs in Brazil: Earnings quality and the cost of equity capital. Research in International Business and Finance, 42, 1057-1073.

http://dx.doi.org/10.1016/j.ribaf.2017.07.041

Silva, R. L M., Nardi, P. C. C., \& Tonani, R. (2016). A relevância do dividendo adicional proposto. Revista Contemporânea de Contabilidade, 13(29), 179-202. http://dx.doi.org/10.5007/2175-8069.2016v13n29p179

Skinner, D. J. (1994). Why firms voluntarily disclose bad news. Journal of Accounting Research, 32(1), 3860. http://dx.doi.org/10.2307/2491386

Soltani, B. (2012). Timeliness of corporate and audit reports: some empirical evidence in the French context. The International Journal of Accounting, 37, 215-246. https://doi.org/10.1016/S0020-7063(02)00152-8

Souza, B. F. \& Nardi, P. C. C. (2018). Influência da opinião do auditor independente no retorno das ações das empresas brasileiras de capital aberto. Contabilidade, Gestão e Governança, 21, 250-270. http://dx.doi.org/10.21714/1984-3925 2018v21n2a6

Slovin, M. B., Sushka, M. E., \& Hudson, C. D. (1990). External Monitoring and its Effect on Seasoned Common Stock Issues. Journal of Accounting and Economics, 12, 397-417. https://doi.org/10.1016/01654101(90)90023-W

STATEMENT OF FINANCIAL ACCOUNTING CONCEPTS No.2 - Qualitative Characteristics of Accounting Information. Disponível em:

https://www.fasb.org/jsp/FASB/Document C/DocumentPage?cid=1218220132599\&acceptedDisclaimer=true Acesso em 15 de julho de 2020

Titman, S. \& Wessel R. (1988). The determinants of capital structure choice. Journal of Finance, 43(1), 1-19. https://doi.org/10.2307/2328319

Trueman, B. (1990). Theories of Earnings-Announcement Timing. Journal of Accounting and Economics, 13(3), 285-301, 1990. https://doi.org/10.1016/0165-4101(90)90035-3

Valle, M. R. (2007). A estrutura de capital das empresas brasileiras num ambiente de altas taxas de juros e na presença de fontes diferenciadas de financiamento. $104 \mathrm{f}$. Tese (Concurso de Livre-docência Departamento de Contabilidade) - Faculdade de Economia, Administração e Contabilidade. Universidade de São Paulo, São Paulo, 2007.

Waddock, S. A. \& Graves, S. B. (1997). The corporate social performance-financial performance link. Strategic Management Journal, 18(4), 303-319. https://www.jstor.org/stable/3088143

Watts, R. L. \& Zirmmerman, J. L. Positive Accounting Theory, Englewood Cliffs, NJ: Prentice-Hall, 1986.

Whitworth, J. D. \& Lambert, T. A. (2014). Office-level characteristics of the Big 4 and audit report timeliness. Auditing: A Journal of Practice \& Theory, 33, 129-152. https://doi.org/10.2308/ajpt-50697

Wooldridge, J. M. (2012). Introdução à Econometria: uma abordagem moderna. Massachusetts: Thomson.

\section{NOTAS}

\section{AGRADECIMENTOS}

Os autores agradecem à Fundação de Amparo à Pesquisa do Estado de São Paulo (FAPESP) (Processo 2017/24426-8), pelo apoio na realização desta pesquisa. 


\section{CONTRIBUIÇÃO DE AUTORIA}

Concepção e elaboração do manuscrito: P. C. C. Nardi

Coleta de dados: N. T. Yagui

Análise de dados: N. T. Yagui, P. C. C. Nardi

Discussão dos resultados: N. T. Yagui, P. C. C. Nardi

Revisão e aprovação: P. C. C. Nardi

\section{CONJUNTO DE DADOS DE PESQUISA}

O conjunto de dados que dá suporte aos resultados deste estudo não está disponível publicamente.

\section{FINANCIAMENTO}

Fundação de Amparo à Pesquisa do Estado de São Paulo (FAPESP). (Processo 2017/24426-8).

\section{CONSENTIMENTO DE USO DE IMAGEM}

Não se aplica.

\section{APROVAÇÃO DE COMITÊ DE ÉTICA EM PESQUISA}

Não se aplica.

\section{CONFLITO DE INTERESSES}

Não se aplica.

\section{LICENÇA DE USO}

Os Direitos Autorais para artigos publicados neste periódico são do autor, com direitos de primeira publicação para a Revista. Em virtude de aparecerem nesta Revista de acesso público, os artigos são de uso gratuito, com atribuições próprias, em aplicações educacionais, de exercício profissional e para gestão pública. A Revista adotou a licença Creative Commons Atribuição 4.0 Internacional - CC BY NC ND. Esta licença permite acessar, baixar (download), copiar, imprimir, compartilhar, reutilizar e distribuir os artigos desde que com a citação da fonte, atribuindo os devidos créditos de autoria. Nesses casos, nenhuma permissão é necessária por parte dos autores ou dos editores. Autores têm autorização para assumir contratos adicionais separadamente, para distribuição não-exclusiva da versão do trabalho publicada nesta revista (ex.: publicar em repositório institucional ou um capítulo de livro).

\section{PUBLISHER}

Universidade Federal de Santa Catarina. Curso de Ciências Contábeis e Programa de Pós-graduação em Contabilidade. Publicação no Portal de Periódicos UFSC. As ideias expressadas neste artigo são de responsabilidade de seus autores, não representando, necessariamente, a opinião dos editores ou da universidade.

\section{EDITORES}

Carlos Eduardo Facin Lavarda e Suliani Rover

\section{HISTÓRICO}

Recebido em: 14/04/2020 - Revisado por pares em: 13/07/2020 - Reformulado em: 22/07/2020 Recomendado para publicação em: 15/10/2020 - Publicado em: 15/01/2021

Uma versão preprint do artigo foi apresentada no XIX USP International Conference in Accounting, 2019. 